\begin{tabular}{|c|c|c|}
\hline $\begin{array}{l}\text { ISSN 2525-4812 (versão online) } \\
\text { ISSN 2238-7641 (versão impressa) } \\
\text { http://www.revistaterceiramargem.com/ } \\
\text { index.php/terceiramargem/index }\end{array}$ & $\begin{array}{c}\text { Recebido em: 14/7/2019 } \\
\text { Aprovado em: 30/2/2020 } \\
\text { Período de publicação: jan./jun., } 2020\end{array}$ & $\begin{array}{c}\text { Revista Terceira } \\
\text { Margem Amazônia } \\
(\text { v. } 6 \cdot \mathrm{n} .14 \cdot \text { Jan./Jun. } 2020)\end{array}$ \\
\hline
\end{tabular}

Como citar o artigo:

GUTIERREZ, D. M. G.; CARVAlho, S. M. S.; RODRIGUES, D. C. B. GARCIA, J. C. D. Política nacional de tecnologia social: reflexões a partir de um grupo de trabalho amazônico. Revista Terceira Margem Amazônia, v. 6, n. 14, p. 31-42, 2020. DOI: http://dx.doi.org/10.36882/2525-4812.2020v6i14p31-42

\title{
POLÍTICA NACIONAL DE TECNOLOGIA SOCIAL: REFLEXÕES A PARTIR DE UM GRUPO DE TRABALHO AMAZÔNICO
}

\author{
Denise Machado Duran Gutierrez ${ }^{l}$ \\ Sônia Marise Salles Carvalho ${ }^{2}$ \\ Débora Cristina Bandeira Rodrigues ${ }^{3}$ \\ Jesus Carlos Delgado Garcia ${ }^{4}$
}

Resumo: O presente texto apresenta uma discussão crítico-reflexiva sobre a Política Nacional de Tecnologia Social, em trâmite no Congresso Nacional Brasileiro desde 2007. Para tal se vale de dados empíricos coletados durante oficina de trabalho coletivo, realizada no VII Workshop de Tecnologia Social do Instituto Nacional de Pesquisas da Amazônia em 2018. A dinâmica de coleta de dados consistiu em acompanhar e relatar as discussões grupais e apresentações finais feitas por diversos subgrupos que procuraram debater o texto da política, sintetizar resultados das discussões e formular propostas que pudessem adensar conteúdo relevante ao documento. Os resultados desse debate são aqui apresentados de modo a contribuir para a ampliação e o aprofundamento da área de avaliação de políticas públicas, com foco em tecnologia social.

Palavras-chave: políticas públicas, tecnologia social, ciência e tecnologia, inclusão social.

\section{NATIONAL SOCIAL TECHNOLOGY POLICY: REFLECTIONS FROM AN AMAZON WORKING GROUP}

\begin{abstract}
The present text presents a critical - reflexive discussion about the National Policy of Social Technology in process in the Brazilian National Congress since 2007. To do so, it uses empirical data collected during a collective workshop, held at the VII Social Technology Workshop of the National Institute of Amazonian Research in 2018. The dynamics of data collection consisted in following up and reporting the group discussions and final presentations made by several subgroups that sought to discuss the text of the policy, synthesize results of the discussions and formulate proposals that could add relevant content to the document. The results of this debate are presented here in order to contribute to the broadening and deepening of the area of evaluation of public policies, focusing on Social Technology.
\end{abstract}

Key words: public policies, social technology, science and technology, social inclusion.

\footnotetext{
${ }^{1}$ Psicóloga, D. Sc. em Saúde Pública, professora da Universidade Federal do Amazonas, Manaus, AM. E-mail: ddgutie@ufam. edu.br

${ }^{2}$ Socióloga, D. Sc. em Sociologia, Centro de Apoio ao Desenvolvimento de Apoio Tecnológico/UnB, Brasília, DF. E-mail: smarises1960@gmail.com

${ }^{3}$ Assistente Social, D. Sc. em Biotecnologia, professora da Universidade Federal do Amazonas, Manaus, AM.. E-mail: deb. band@gmail.com

${ }^{1}$ Teólogo, D. Sc. em Ciências Sociais, professor da Universidade Federal do Recôncavo Baiano, Salvador, BA. E-mail: jesus. carlos@ufrb.edu.br
} 


\section{Introdução}

Avanços e melhoras na qualidade de vida, lutas e conflitos diversos, dominação e exclusão nas sociedades têm sido historicamente marcados pela emergência e pelo desenvolvimento de conhecimentos e tecnologias em suas várias formas. Um modo de consolidar o conhecimento e a aplicação ampla de tecnologias nas sociedades modernas é por meio da criação de políticas públicas que gerem um tipo de pacto sociojurídico que permita acesso aos benefícios previstos na política pública por um amplo conjunto de pessoas. A política pública, nesse sentido, reconhece direitos e implementa ações que efetivam esses direitos.

As tecnologias sociais, embora há muito presentes na vida das comunidades empobrecidas, consagradas enquanto instrumentos de melhoras importantes e de impacto social - por exemplo, nas condições de saúde de crianças até 5 anos de idade pelo uso do soro caseiro - têm sido vistas com desprezo e não têm assumido o protagonismo que seria necessário na geração de políticas públicas.

No campo das políticas de ciência e tecnologia no País, principal área com a qual a tecnologia social dialoga e campo gerador de conhecimentos que a compõem, o que se tem visto é a adoção de visões convencionais de tecnologia e de políticas de C\&T voltadas à inovação tecnológica que não abarca tecnologias sociais, mas, ao contrário, descarta o componente sociotécnico e se volta para pretensamente fortalecer o parque tecnológico industrial. Diversos autores põem em questão essas ideias de inovação tecnológica que informam as políticas atuais de C\&T, demonstrando claramente que a tecnologia de ponta, de fato apropriada pelas indústrias no Brasil, é produzida em circuitos internacionais em grandes centros de desenvolvimento tecnológico, em países de primeiro mundo que detêm a hegemonia política, econômica e intelectual (Dagnino entrevista Perseu Abramo). Ademais desafiam o próprio processo produtivo de tais tecnologias afirmando que são, sempre que possível, copiadas, roubadas ou compradas, numa lógica selvagem que nada tem a ver com desenvolvimento social e com os fundamentos da tecnologia social.

No governo atual esse pensamento está implícito no Ministério Setorial, em que a ciência e a tecnologia vêm associadas à inclusão social, abrangendo uma concepção que perpassa a utilização social da tecnologia, à dimensão intrínseca de sua abordagem social, ou seja, uma tecnologia que se apresenta como assistiva e se confunde com ela. Assim tem sido no Ministério de Ciência, Tecnologia, Inovações e Comunicações com a presença de uma secretaria de tecnologia assistiva permeada por uma política pública limitada à sua natureza inclusiva e assistencial.

Como ponto fora dessa tendência, a disposição institucional de se ter no Brasil uma lei que configurasse a política pública de tecnologia social surgiu em 2005 na Secretaria de Ciência e Tecnologia para Inclusão Social (Secis), no âmbito do Ministério da Ciência e Tecnologia (MCT). A Secis encarregou o Instituto de Tecnologia Social (ITSBRASIL) de uma proposta de lei, que, uma vez elaborada, foi apresentada e discutida no Fórum de Tecnologia Social. A proposta de legislação foi acolhida e apreciada no âmbito da Secis com o intuito de que o poder executivo a enviasse à Câmara dos Deputados, de forma semelhante à criação de outras políticas públicas. Em 2007, esse texto foi apresentado na Câmara dos Deputados por Rodrigo Rollemberg (PSBDF) e Luiza Erundina (PSB-SP), constituindo o Projeto de Lei ${ }^{\circ} 3.449 / 2008$, que após diversas tramitações foi finalmente arquivado. Em 2015, o senador Rodrigo Rollemberg apresentou o 
Projeto de Lei no 3.329/15, para criação da Política Pública Nacional (PNTS), que recolhe pontos substanciais daquela proposição, mas perde também dispositivos interessantes. Atualmente o Projeto de Lei $n^{0}$ 3.329/15 aguarda apreciação do Senado Federal, como requisito prévio à sanção pelo presidente da República.

A proposta entende que as tecnologias sociais devem ser voltadas para a solução de problemas básicos enfrentados por pessoas concretas: suprimento de água potável, alimentação, educação, energia, habitação, renda, saúde e meio ambiente. Conforme o documento em questão, as atividades de tecnologia social devem estar presentes nas políticas e nos projetos de:

1. Produção e democratização do conhecimento e da ciência, tecnologia e inovação.

2. Iniciação científica e tecnológica e inclusão digital.

3. Saúde.

4. Energia, meio ambiente, recursos hídricos, saneamento básico e gestão de resíduos.

5. Educação, arte, cultura, lazer e extensão universitária.

6. Juventude e direitos da criança e do adolescente.

7. Promoção da igualdade em relação à raça e ao gênero e de pessoas com deficiência.

8. Segurança alimentar, geração de trabalho e renda e moradia popular.

9. Tecnologia de assistência social, agricultura familiar, agroecologia e reforma agrária.

10. Microcrédito e economia solidária.

11. Desenvolvimento local participativo.

Uma vez aprovado pelo Senado, o projeto deve seguir para sanção presidencial, caso não haja recurso para análise pelo plenário da câmara. No entanto, verifica-se que, desde então, não houve avanço nessa tramitação, não tendo até o momento se tornado política vigente.

Busca-se, no presente texto, trazer uma discussão crítico-reflexiva sobre essa proposta de política a partir de relatos de discussões grupais e apresentações finais de um grupo de trabalho (GT) feitas por diversos subgrupos que procuraram debater o texto da política, sintetizar resultados das discussões e formular propostas que pudessem adensar conteúdo relevante à compreensão do documento. Os resultados desse debate são aqui apresentados de modo a contribuir com a ampliação e o aprofundamento da área de avaliação de políticas públicas com foco em tecnologia social.

\section{Metodologia}

Trata-se aqui do emprego da abordagem qualitativa de pesquisa, que consiste em utilizar relatos livres, dos participantes, sobre determinada temática, para compor um corpus analítico em forma de linguagem (texto), que permite acessar opiniões, atitudes, valores, representações e outras formas simbólicas, construídas em relação a determinado fenômeno em pauta (MINAYO, 
2019). Desta feita se utilizou a técnica denominada grupo de trabalho (GT) para discutir essa política. O trabalho foi organizado conforme as seguintes etapas:

1. Orientação da proposta metodológica da atividade.

2. Leitura coletiva do Projeto de Lei $n^{0} 3.329 / 15$.

3. Formação de grupos de trabalho com análise aprofundada dos artigos do projeto de lei e sua aplicabilidade no desenvolvimento territorial da Amazônia.

4. Socialização das análises dos GTs com o conjunto de todos os participantes do workshop.

5. Leitura da sistematização das ideias, complementadas pela análise das coordenadoras da atividade.

Para melhor detalhamento é preciso esclarecer que inicialmente foram dadas orientações para a composição dos grupos de trabalho e distribuição dos artigos do projeto de lei. Houve assim a composição de cinco GTs, com número igual de participantes, de formação multidisciplinar e oriundos de diferentes setores da sociedade. Na sequência se procedeu ao estudo do documento em cinco grupos, sendo que cada grupo ficou responsável por refletir um dos temas abaixo:

1. Conceito e Finalidade

2. Princípios da Lei

3. Objetivos da Lei

4. Instrumentos da Política

5. Diálogos e Transversalidades da Política

Após a leitura do documento e feitas as aproximações conceituais de termos-chaves presentes no documento (inovação, economia solidária, tecnologia e ciência), procedeu-se à explanação da história dessa lei e de como foi pensada pelos representantes da sociedade civil, governo e universidade. A proposta inicial não foi contemplada em sua íntegra pelo projeto de lei, que saiu do executivo para o legislativo, passando por três comissões no Senado, no período de 2001 a 2015. Foi para a Câmara dos Deputados e aguarda assinatura do presidente. Foi também esclarecido como a proposta original buscava o fortalecimento dos vínculos entre público-privado na vertente da quíntupla hélice (interação universidade, empresa, governo, terceiro setor e meio ambiente).

Organizaram-se os grupos com 15 participantes, com a presença de um coordenador e um relator de cada grupo, por um tempo de 25 minutos para aprofundar os artigos da lei e propor melhorias para sua aplicabilidade no território da Amazônia. Esses grupos eram compostos por pesquisadores, estudantes, líderes comunitários, produtores rurais, gestores públicos e representantes de órgãos de fomento de tecnologia social.

Por fim foi feita a sistematização das reflexões do GT em cartazes e a socialização em plenária. Depois da socialização dos GTs foi aberta discussão com a plenária para apreciação e incorporação de novas ideias e, ao final, se procurou sistematizar o pensamento dos integrantes dessa oficina. 


\section{Resultados e Discussão}

Para efeitos de organização do material de análise, abaixo, optou-se por apresentar as sessões da PNTS seguidas das considerações sintetizadas emergentes nas discussões dos GTs, em itálico. Na sequência procurou-se apresentar as reflexões sobre o material, associando-o a elementos da literatura e procurando tecer uma articulação entre esses vários elementos de modo a avançar na discussão de cada sessão do documento.

\section{Conceito e Finalidade do Projeto de Lei}

No Projeto de Lei $\mathrm{n}^{\mathrm{o}} 3.329 / 15$, no Art. $1^{\mathrm{o}}$, $\S 1^{\circ}$, ficam definidas a tecnologia social e a inovação social da seguinte forma:

$\S 1^{\circ}$ Para os efeitos desta lei, considera-se:

I -Tecnologia social: atividades voltadas para a inclusão social e a melhoria da qualidade de vida, desenvolvidas mediante processo coletivo de organização, desenvolvimento e aplicação, que tenham por finalidade planejamento, pesquisa, desenvolvimento, criação, adaptação, difusão e avaliação de:

a) técnicas, procedimentos e metodologias;

b) produtos, dispositivos, equipamentos e processos;

c) serviços;

d) inovações sociais organizacionais e de gestão.

II - Inovação em tecnologia social: introdução de novas tecnologias sociais, assim como de melhorias, avanços e aperfeiçoamentos em tecnologias sociais existentes, no ambiente produtivo ou social.

GT: "A proposta aqui foi pensar a tecnologia social em sua abrangência e em sua regionalização, haja vista a diversidade do território".

Embora a ampla abrangência da lei possa ser vista como ponto positivo da proposição, por trazer em pauta diversas áreas e formas de aplicação de tecnologia social, é preciso corporificá-la em seus contextos específicos. Diversos conceitos são assumidos como tácitos, mas se inserem num campo de debates em que faltam consensos. Esse é o caso dos conceitos de qualidade de vida, inovação, inovações sociais e outros presentes no corpo da política em outras sessões.

A ideia de regionalização e consideração das diversidades nos convocam a várias considerações:

A Questão Amazônica, considerando a região em suas peculiaridades socioculturais e históricas, tem desaparecido da pauta das políticas de C\&T no País. Embora se reconheça, por vezes romanticamente, a potencial importância da biodiversidade na região, a questão da sociodiversidade não tem sido contemplada. Se pensarmos que a política nada mais faz do que cristalizar o pacto social, seja ele explícito ou tácito, então entendemos a relação do texto com o apagamento 
das figuras do indígena e do caboclo - matrizes socioculturais locais - e das formas associativas de produzir bens e desenvolver trabalho. A lógica que a lei informa não dialoga com os saberes locais e as formas originais adotadas pelas populações autóctones. Sobre essa questão do apagamento simbólico do indígena podemos recorrer aos escritos de Sampaio (2012).

A questão das dificuldades de gestão de empreendimentos econômicos em tecnologia social é um dos indicadores das fragilidades de sua implementação e sustentabilidade em região amazônica (RUTKOWSKI, 2019).

Ademais o desejável processo de construção de tecnologias tem como pressuposto formas coletivas de organização social e estabelecimento de fortes laços de cooperação tecidos nas redes de relações sociais. No entanto, é sabido que apresenta como uma de suas dificuldades o fato de que o associativismo e cooperativismo não conseguiram desenvolver-se em sua plenitude em nossa região, enfrentando muitos obstáculos para sua consolidação (POTIGUAR-JUNIOR, 2008).

Essa dificuldade tem, por certo, múltiplas codeterminações, dentre as quais podemos pensar no fato de que quando falamos de Amazônia estamos nos referindo a um objeto extremamente heterogêneo, um verdadeiro mosaico marcado por diversos universos simbólicos, rivalidades ancestrais, elementos em competição e luta, que, em confronto com os valores hegemônicos dos colonizadores, adotaram diversas vias de expressão e resistência (HECK et al., 2005).

\section{Princípios da Lei}

Art. $2^{\circ}$ São princípios da Política Nacional de Tecnologia Social: I - respeito aos direitos fundamentais, em especial ao: a) direito ao conhecimento e à educação; b) direito de participar do patrimônio científico, tecnológico e cultural; c) direito à vida, à alimentação e à saúde; d) direito ao desenvolvimento; e) direito de usufruir dos benefícios gerados pela tecnologia; II - adoção de formas democráticas de atuação.

GT: "Promover capacitação, interação, desenvolvimento, publicidade e relevância para a pesquisa em articulação com propostas de desenvolvimento de tecnologia social”.

"Necessidade de abrangência da lei para além dos excluídos e uma regionalização com inserção da questão cultural”.

"Processo artesanal e tradição como valor agregado à tecnologia".

"Respeito à forma de construção da cultura local com adequação das legislações".

Pensar políticas públicas para a Amazônia requer necessariamente o entendimento do contexto sociocultural no qual encontram-se imersos seus povos, compreendendo estes a partir do estabelecimento das relações homem-natureza, concretizadas no cotidiano em suas diversas expressões e manifestações de atividades práticas, o que constitui grande medida a forma de ser e viver na região (RODRIGUES, 2001). Nessa área é possível identificar uma diversidade de grupos sociais constituídos, historicamente, como: pequenos produtores, ribeirinhos, trabalhadores rurais, indígenas, artesãos, extrativistas, colonos, fazendeiros, pescadores, entre outros (CHAVES, 2001). 
Os diferentes segmentos sociais identificados construíram, ao longo de suas histórias e trajetórias na região, formas específicas de uso, manejo e apropriação dos recursos naturais, um lidar diferenciado com a natureza, um saber-fazer particular, estabelecendo códigos e singularidades, construindo uma linguagem peculiar no trato homem-natureza, e que precisam ser considerados no processo de construção e implementação de políticas públicas na região.

Importante ressaltar que as diversas formas de uso e manejo dos recursos naturais utilizados pelas populações tradicionais indígenas e não indígenas da Amazônia podem ser encontradas na alimentação, no vestuário, na atividade produtiva, no transporte, na moradia, caça de animais e pássaros da floresta (SOUZA, 1994).

Assim, pensar a abrangência da lei considerando regionalização com inserção da questão cultural, visualizando os processos artesanais e a tradição como valor agregado à tecnologia, com respeito à forma de construção da cultura local, torna-se imprescindível para consolidar cidadania promovendo resgate e valorização dos conhecimentos tradicionais e da cultura, a fim de que essas sociedades sejam fortalecidas em sua autonomia, fomentando formas de desenvolvimento originárias de sua própria criatividade de acordo com valores locais.

Pode-se dizer que as formas democráticas de funcionamento são o principal fundamento de uma tecnologia social, pois em princípio parte de uma demanda social e finaliza-se em atendê-la, percorrendo assim um ciclo em que as necessidades de um coletivo estão centrais. Esse coletivo precisa ser ouvido, tomado como ator ativo, protagonista de seu destino e detentor de direitos.

Outra preocupação do grupo de discussão girou em torno da necessidade de capacitação, educação e conhecimento sobre as tecnologias sociais e, mais amplamente, um maior acesso ao conhecimento como um todo. Numa sociedade como a nossa, chamada Sociedade do Conhecimento, diversas formas de acesso a bens e serviços são mediadas por conhecimento de algum tipo (locais, processos, saberes, manipulação de tecnologias de informação, notícia, mídias sociais, etc.).

Identificam também como importante o reconhecimento, a valorização e legitimação da cultura local como forma de afirmação de identidades e resgate de autoestima do homem amazônico, historicamente e simbolicamente excluído, estigmatizado e desconstruído em suas raízes fundamentais. A recorrência desse aspecto, expresso de variadas formas: regionalização, respeito à cultura, tradição como valor agregado, nos deixa ver a centralidade dessa preocupação para esse grupo amazônico.

\section{Objetivos da Lei}

Art. $3^{\circ}$ São objetivos da Política Nacional de Tecnologia Social: I - proporcionar soluções derivadas da aplicação de conhecimentos, da ciência e tecnologia e da inovação para atender necessidades e demandas de maior qualidade de vida da população em situação de exclusão social; II - integrar as tecnologias sociais com a Política Nacional de Ciência, Tecnologia e Inovação; III - promover a integração social e econômica das tecnologias sociais na economia do País e no desenvolvimento local sustentável; IV - contribuir para a interação entre as esferas do saber acadêmico e do saber popular; $\mathrm{V}$ - disponibilizar políticas adequadas de promoção e fomento das 
tecnologias sociais mediante a criação de infraestruturas necessárias, assim como de instrumentos de crédito e de formação e capacitação de recursos humanos; VI - estimular o associativismo e a criação, a incubação e o fortalecimento de empreendimentos cooperativos e solidários capazes de realizar cooperações técnico- científicas com centros de geração de conhecimento e de aplicar ou reaplicar tecnologias sociais inovadoras.

GT: "Entende-se que o maior entrave para a implementação da lei no País se dá devido à falta de empenho do cidadão em apropriar-se do conhecimento, para então pôr em prática o que rege a lei. No entanto, se faz necessária a representatividade por individuos que estejam aptos a contribuir para uma sociedade melhor, agregando valor para o País".

No relato acima vemos que, de um lado, o grupo afirma a necessidade de maior participação e representação social, tendo em vista a melhoria das condições de vida em toda a sociedade. Paradoxalmente, e de outro lado, o grupo adota aqui uma perspectiva centrada no indivíduo, culpabilizando-o. Como expresso, se trataria de "falta de empenho do cidadão". Ao assim fazê-lo reafirma os processos sutis de exclusão em que os indivíduos passam a ser responsabilizados por sua própria exclusão, sem deixar ver os mecanismos perversos que regem os processos invisíveis de exclusão social (SAWAIA, 1999) ${ }^{5}$. A culpabilização, em sua forma extrema, seria a culpabilização de si mesmo pelas mazelas sociais vividas. Juntamente com a competitividade nas relações sociais, a culpabilização do indivíduo faz parte do que Guareschi (1999) ${ }^{6}$ denomina pressupostos psicossociais da exclusão, demonstrando como as consciências podem ser de tal modo amordaçadas e capturadas por símbolos e valores hegemônicos, que, num processo pouco ou nada consciente, passam a atacar a si mesmas e desvalorizar-se.

\section{Instrumentos da Política}

Art. $4^{\circ}$ São instrumentos da Política Nacional de Tecnologia Social: I - os programas transversais elaborados em parceria com os órgãos públicos correspondentes; II - os fundos setoriais de ciência, tecnologia e inovação; III - o Fórum Nacional de Tecnologia Social; IV - o Centro Brasileiro de Referência em Tecnologia Social (CBRTS); V - a Rede de Tecnologia Social; VI - a extensão universitária; VII - os convênios, com entidades públicas ou privadas, nacionais ou estrangeiras, para desenvolvimento de tecnologias sociais, inclusive quando envolverem a obtenção de recursos técnicos, humanos ou financeiros; VIII - os sistemas de monitoramento, cadastros técnicos de atividades e bancos de dados.

"Crítica: ser a política voltada para a população em situação de exclusão social".

"Incorporar a integração social, cultural, ambiental e econômica".

"Qual o papel desse instrumento? Como interagir com ele? Como deve ser feito?". "Esclarecer os instrumentos da PNTS numa linguagem acessivel".

\footnotetext{
${ }^{5}$ SAWAIA, B. (Org.). As artimanhas da exclusão - análise psicossocial e ética da desigualdade social. Petrópolis: Vozes, 1999.

${ }^{6}$ GUARESCHI, P. A. Pressupostos psicossociais da exclusão: competitividade e culpabilização. In: SAWAIA, B. (Org.). As artimanhas da exclusão - análise psicossocial e ética da desigualdade social. Petrópolis: Vozes, 1999.
} 
O fato de apresentar-se como política voltada aos "excluídos" é vista pelo grupo como algo negativo, pois marca a diferença num grupo que, ao contrário, deseja afirmar a igualdade e enfatizar os aspectos mais universais de seu pertencimento. Parece haver um clamor no grupo pela igualdade e integração multidimensional na vida dos grupos sociais - social, cultural, ambiental e econômica. A síntese seria: ser igual, observando, no entanto, as diferenças.

Destaca-se o fato de que vários dos instrumentos previstos na política são iniciativas que, no passado, foram implantadas em diversos contextos, porém ficaram estagnadas devido às mudanças nas políticas de diversos governos em suas últimas gestões, como é o caso do Fórum Nacional de Tecnologia Social (com última publicação em 2006), o Centro Brasileiro de Referência em Tecnologia Social (com banco de projetos recentemente atualizado pela Fundação Banco do Brasil) e da Rede de Tecnologia Social (com site fora de operação há longo tempo). Esse passado recente não recomenda a adoção de tais instrumentos como confiáveis, os quais já têm se mostrado pouco sustentáveis e com baixa adesão. $O$ grupo não conhece e não entende exatamente o que cada um desses instrumentos significa e qual sua potência para, de fato, instrumentalizar a política pública.

A linguagem adotada na política é tomada também como entrave para seu entendimento pelos grandes grupos populares, supostamente tomados como seu objeto. É preciso realizar esforços no sentido de traduzir de forma mais clara e compreensível o texto da política.

\section{Diálogos e Transversalidades da Política}

Art. $5^{\circ}$ Incluem-se na Política Nacional de Ciência, Tecnologia e Inovação as atividades de tecnologia social. Parágrafo único. As atividades de tecnologia social receberão tratamento idêntico ao conferido às demais atividades desenvolvidas no setor de ciência, tecnologia e inovação. Art. $6^{\circ}$ As atividades de tecnologia social deverão ser incluídas nas políticas e nos projetos de: I - produção e democratização do conhecimento e da ciência, tecnologia e inovação; II - iniciação científica e tecnológica e inclusão digital; III - saúde; IV - energia, meio ambiente, recursos hídricos, saneamento básico e gestão de resíduos; V - educação, arte, cultura, lazer e extensão universitária; VI - juventude e direitos da criança e do adolescente; VII - promoção da igualdade em relação à raça e ao gênero e de pessoas com deficiência; VIII - segurança alimentar, geração de trabalho e renda e moradia popular; IX - tecnologia de assistência social, agricultura familiar, agroecologia e reforma agrária; X - microcrédito e economia solidária; XI - desenvolvimento local participativo.

"Melhor comunicação da lei com linguagem clara e objetiva para que haja compreensão, apreensão e participação em todo o ciclo da política".

"Educação e formação adequada nas questões referentes ao tema".

"Promover a integração sustentável com transversalidades, intersetorialidade em diálogo interdisciplinar com outras politicas para além das tecnologias".

"Necessidade de mobilização das forças políticas dos movimentos para fortalecer essa lei". 
"Impacto da lei na proposta de mudar os paradigmas da produção do conhecimento fazendo os usos sociais da ciência".

"Pensar para a biodiversidade, a proteção das tradições por meio de indicação geográfica e marca coletiva, direito autoral, etc.".

"Necessidade de aprendizagem no acesso às políticas com elaboração dos projetos para editais e no monitoramento da política".

As formulações tecidas pelo grupo deixam ver uma complexidade de fatores entendidos pelos sujeitos como importantes para dar corpo à política no mundo concreto da vida dos grupos sociais interessados:

1. Não basta aprovar a lei, é preciso divulgá-la e fazê-la entendida por todos.

2. A educação é elemento fundamental em todos os momentos da política.

3. Transversalidade, intersetorialidade e diálogo interdisciplinar integrando atores, conhecimentos, segmentos sociais, organizações, etc.

4. Atores políticos em ação, comprometidos com o bem comum.

5. Adoção de certa forma de fazer ciência, chamada "novo paradigmática", que saia das caixinhas disciplinares e alienantes do conhecimento científico e saiba dialogar com o conhecimento tradicional.

6. Esclarecer e dar acesso aos benefícios da política, inclusive permitindo seu monitoramento coletivo.

\section{Considerações Finais}

A proposição da política parece trazer implícita a compreensão de que a tecnologia social, embora de importância para integração de diversas fontes de conhecimento e combate às desigualdades sociais, não tem recebido atenção necessária. Esse ponto fica claro no tópico em que pede igualdade de tratamento com outras perspectivas tecnológicas de maior prestígio na área científica hegemônica.

Nos últimos anos temos visto em nosso país o desmonte do sistema de ciência e tecnologia, bem como o ataque ao sistema educacional universitário. A ciência e tecnologia, tomadas em sua acepção de maior prestígio, passaram a ser vistas como 'dispêndio de recursos', ao invés de via de desenvolvimento e superação de condições de atraso. A universidade pública brasileira, da mesma forma, recebeu diversas imposições restritivas e foi tachada de espaço de ideologização do pensamento, enquanto, todos sabemos, que em sua trajetória histórica tem sido espaço para o exercício da inteligência e debate do livre pensamento. Nesse cenário, adverso ao livre pensamento e refratário aos interesses e às necessidades de cunho social, resta pouca chance de avanços na área de políticas públicas de inclusão social, como é o caso da Política Nacional de Tecnologia Social. 
Uma demanda clara presente nos relatos foi a necessidade de todos participarem de outras oportunidades de eventos abertos ao público para criação de um ambiente favorável ao desenvolvimento e troca de conhecimento sobre tecnologia social. Embora o evento esteja em sua oitava versão anual, ainda há muito desconhecimento sobre o conceito, sua relevância e formas de construção.

O grupo apresenta, em seu conjunto de reflexões, elementos muito ricos em suas formas de compreensão da realidade, suas demandas de participação, busca de valorização da cultura local e integração de conhecimentos. Demonstra um ambiente simbólico em que aparecem aspirações pela busca de conhecimento, reivindica acesso à educação, expressa esforço em compreender sua realidade e em especial a proposta formal de política pública de tecnologia social.

Em tempos de crise moderna que afeta todas as dimensões do ser humano, a tecnologia social significa a proposta de um modelo civilizador sofisticado porque atribui aos saberes tradicionais o cerne da tecnologia que une o homem ao seu lugar e dá sentido às suas atividades laborais, assim como potencializa os recursos tecnológicos já existentes gerando efetividade na reprodução ampliada da vida.

\section{Referências}

CHAVES, M. P. S. R. Uma experiência de pesquisa-ação para gestão comunitária de tecnologias apropriadas na Amazônia: o estudo de caso do assentamento de Reforma Agrária Iporá. 2001. 207 f. Tese (Doutorado) - Universidade Estadual de Campinas, Campinas.

GUARESCHI, P. A. Pressupostos psicossociais da exclusão: competitividade e culpabilização. In: SAWAIA, B. (Org.). As artimanhas da exclusão - análise psicossocial e ética da desigualdade social. Petrópolis: Vozes, 1999.

HECK, E.; LOEBENS, F.; CARVALHO, P. D. Amazônia indígena: conquistas e desafios. Estudos Avançados, v. 19, n. 5, p. 237-255, Apr. 2005.

MINAYO, M. C. S. Ciência, técnica e arte: o desafio da pesquisa social. Disponível em: http://scholar. google.com.br/scholar_url?url=http://www.densf.xpg.com.br/ciencia_tecnica_e_arte_o_desafio_da_pesquisa_social.doc\&hl=pt-BR\&sa=X\&scisig=AAGBfm1XSDD6cW2ZRWEUfwyO5NQ -jAMj4Q\&noss1=1\&oi=scholarr. Acesso em: 03 jul. 2019.

POTIGUAR-JUNIOR, P. L. T. Caminhos e (des)caminhos do associativismo entre os "povos das águas": a Associação Beneficente dos Pescadores de Marudá, Pará. 2008. 157 f. Dissertação (Mestrado em Agricultura Familiar e Desenvolvimento Sustentável) - Universidade Federal do Pará, Belém, PA.

RODRIGUES, D. C. B. A relação homem - natureza nas formas de uso e propriedade da terra na Amazônia: um estudo baseado nas Comunidades do Assentamento Iporá. 2001. 110 f. Dissertação (Mestrado em Sociedade e Cultura na Amazônia) - Universidade Federal do Amazonas, Manaus.

RUTKOWSKI, J. Sustentabilidade de empreendimentos econômicos solidários: outro mundo, outra economia, outra engenharia. Trabalho apresentado no V Encontro Internacional de Economia Solidária "O discurso e a prática da economia solidária”. Disponível em: http://sites.poli.usp.br/p/augusto.neiva/ nesol/ Publicacoes/V\%20Encontro/Artigos/Tecnologia/TEC-05.pdf. Acesso em: 03 jul. 2019.

SAMPAIO, P. M. M. Fronteras de la libertad: tutela indigena en el Diretorio Pombalino e en la Carta Regia de 1798. Boletin Americanista, v. 64, p. 13-24, 2012. 
SAWAIA, B. (Org.). As artimanhas da exclusão - análise psicossocial e ética da desigualdade social. Petrópolis: Vozes, 1999.

SOUZA, M. Breve história da Amazônia. 2. ed. São Paulo: Editora Marco Zero, 1994. 